\title{
Wind Speed Influences on Marine Aerosol Optical Depth
}

\author{
Colin O'Dowd, ${ }^{1}$ Claire Scannell, ${ }^{1,2}$ Jane Mulcahy, ${ }^{1,3}$ and S. Gerard Jennings ${ }^{1}$ \\ ${ }^{1}$ School of Physics \& Centre for Climate and Air Pollution Studies, Environmental Change Institute, \\ National University of Ireland Galway, University Road, Galway, Ireland \\ ${ }^{2}$ Université Paris 6, LATMOS/IPSL, CNRS/INSU, 75005 Paris, France \\ ${ }^{3}$ Global Model Evaluation and Development, Met Office, Exeter, Devon EX1 3PB, UK
}

Correspondence should be addressed to Colin O’Dowd, colin.odowd@nuigalway.ie

Received 18 February 2010; Revised 18 July 2010; Accepted 21 August 2010

Academic Editor: David Kieber

Copyright () 2010 Colin O’Dowd et al. This is an open access article distributed under the Creative Commons Attribution License, which permits unrestricted use, distribution, and reproduction in any medium, provided the original work is properly cited.

\begin{abstract}
The Mulcahy (Mulcahy et al., 2008) power-law parameterization, derived at the coastal Atlantic station Mace Head, between clean marine aerosol optical depth (AOD) and wind speed is compared to open ocean MODIS-derived AOD versus wind speed. The reported AOD versus wind speed $(\mathrm{U})$ was a function of $\sim U^{2}$. The open ocean MODIS-derived AOD at $550 \mathrm{~nm}$ and $860 \mathrm{~nm}$ wavelengths, while in good agreement with the general magnitude of the Mulcahy parameterization, follows a power-law with the exponent ranging from 0.72 to 2.47 for a wind speed range of $2-18 \mathrm{~m} \mathrm{~s}^{-1}$. For the four cases examined, some MODIS cases underestimated AOD while other cases overestimated AOD relative to the Mulcahy scheme. Overall, the results from MODIS support the general power-law relationship of Mulcahy, although some linear cases were also encountered in the MODIS dataset. Deviations also arise between MODIS and Mulcahy at higher wind speeds $\left(>15 \mathrm{~m} \mathrm{~s}^{-1}\right.$ ), where MODIS-derived AOD returns lower values as compared to Mulcahy. The results also support the suggestion than wind generated sea spray, under moderately high winds, can rival anthropogenic pollution plumes advecting out into marine environments with wind driven AOD contributing to AOD values approaching 0.3.
\end{abstract}

\section{Introduction}

Sea spray aerosol is one of the largest natural contributors to the global aerosol loading and thus plays an important role in the global radiative budget $[1,2]$. Submicron size aerosols are especially relevant in terms of cloud condensation nuclei [3], while both sub- and supermicron sizes contribute to aerosol scattering [4] and to aerosol optical depth [5]. Both of these effects suggest that sea spray aerosol plays an important role in the global radiative budget, contributing to the aerosol climate effect $[6,7]$.

Mulcahy et al. [5] established that under moderate to high wind speed conditions, AOD associated with sea spray followed a power-law wind-speed dependency with an exponent of $\sim 2$. At moderately high wind speeds, sea sprayderived AOD reached the order of 0.35 , often exceeding AOD associated with pollution plumes over oceanic regions. The relationship of Mulcahy et al. [5] has recently been compared to model-predicted AOD from sea spray sources by Madry et al. [8]. In the latter study, they found that model-derived
AOD also followed a wind speed square function, and that the formulation proposed by Mulcahy et al. [5] was highly correlated to the modeled-derived AOD values.

Mulchay et al. [5] report AOD values for clean marine air which are significantly higher than those previously reported (e.g., Smirnov et al. [9]), most likely due to a wider wind speed range in Mulcahy et al. [5] along with extensive filtering and analysis procedures used; however, the Mulcahy et al. [5] data were taken in the coastal environment, and apart from the aforementioned modeling study, they have not been compared to open-ocean measurements of AOD. In this study, we compare the Mulcahy et al. [5] AOD-wind speed relationship to MODIS-derived AOD versus wind speed. The comparison is done for two remote open ocean regions.

\section{MODIS AOD and Wind Speed Data}

Clean air masses are essential to ensure that the only contribution to the AOD is from natural aerosols, in this 


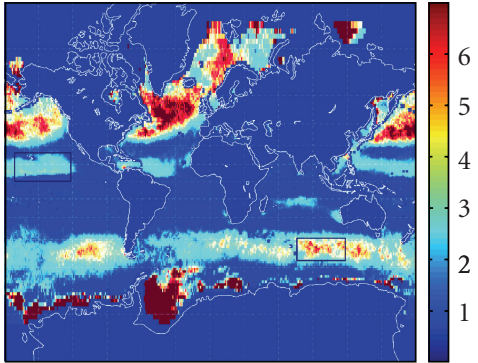

Sea spray mass emissions $10^{10}\left(\mathrm{~kg} \mathrm{~m}^{-2} \mathrm{~s}^{-1}\right)$

(a)

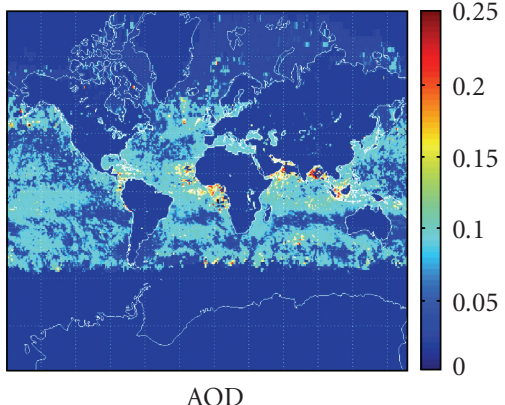

(b)

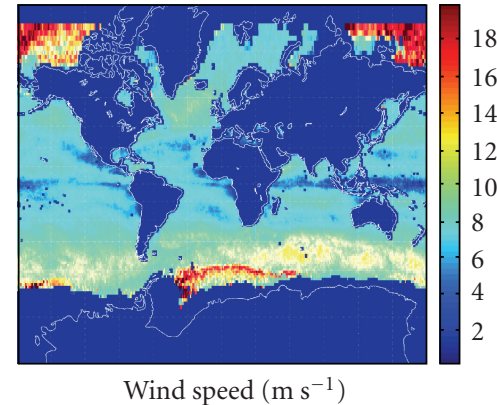

(c)

FIgURE 1: (a) depicts a global sea spray mass emissions map scheme illustrating areas for which AOD was examined in the North Pacific and Southern oceans, (b) illustrates global annual average AOD for June 2006, and (c) shows the average monthly wind speed.

case sea spray aerosols. This is achieved by choosing remote marine locations away from large land masses, by examining the air mass trajectories over each location and choosing only those days for which the air mass has not passed over land in the five days previous. These periods were chosen based on clean marine air systems observed using HYSPLIT back trajectories over two specific grids for 2006. The HYSPLIT or HYbrid Single Particle Lagrangian Integrated Trajectory model run by NOAA can compute simple forward or backward air parcel trajectories from any starting or finishing grid point. It can run complex dispersion and deposition simulations and compute the advection of an ensemble of pollutants or the advection of a single pollutant. For this work, its ability to compute multiple and single backward air mass trajectories from a particular location was utilised to determine the direction of approaching air mass trajectories. For further information see [10].

For this analysis, $1^{\circ} \times 1^{\circ}$ resolution C005 MODIS daily AOD data taken from the Ocean level 3 MODIS Atmosphere Daily Global Product for 2006 at $550 \mathrm{~nm}$ and $860 \mathrm{~nm}$ were utilised. Two grid areas were chosen in remote marine locations (Figure 1): one in the north Pacific $\left(0^{\circ} \mathrm{N}-20^{\circ} \mathrm{N}\right.$ and $\left.180^{\circ} \mathrm{W}-110^{\circ} \mathrm{W}\right)$ and one in the Southern ocean $\left(40^{\circ} \mathrm{S}-\right.$ $60^{\circ} \mathrm{S}$ and $120^{\circ} \mathrm{E}-80^{\circ} \mathrm{E}$ ), denoted hereafter as Grid 1 and Grid 2. Shown in the figure is a sea spray mass emission rate along with MODIS-derived AOD. The additional criteria used for selection of the grids were as follows: only clean air masses were examined as determined by back-trajectory analysis; there must be no cloud contamination; there must be variable wind speeds during the period. Grid 1 and grid 2 were analysed for January and December 2006 and July and December 2006, respectively. The areas chosen coincided with areas of high sea spray aerosol concentrations. Such large areas were chosen in order to sample a complete range of wind speeds under the strict criteria that were utilized. $\mathrm{AOD}$ and wind speed data were retrieved daily for the month long periods outlined for both grids. Wind speed data was retrieved from the SeaWinds instrument on the QuickSCAT satellite. SeaWinds is a microwave radar that measures nearsurface wind speed and direction with a swath resolution of $0.25^{\circ} \times 0.25^{\circ}$. It was launched into a polar, sun-synchronous orbit with $98.6^{\circ}$ inclination and with a local equator crossing time at the ascending node of $6: 00 \mathrm{am} \pm 30 \mathrm{mins}$ and the descending node of 18:00 \pm 30 mins. Data is available in daily, weekly, and monthly formats. For this analysis, wind speed was interpolated to a $1^{\circ} \times 1^{\circ}$ grid to compare to a $1^{\circ} \times 1^{\circ}$ AOD grid, and each wind speed data point was matched to its corresponding AOD data point at each time and location. Since the ascending equatorial crossing time of MODIS AQUA is approximately 1:30 am, 4.5 hours prior to QuikSCAT, care was taken in choosing times and locations where wind speed variability was minimal. Between 2000 and 5000 AOD data points were binned according to wind speed intervals for each month for each grid.

Clouds are characterised by high optical depths, and AOD measurements cannot be made in areas of cloud cover. Therefore, it is imperative for accurate AOD measurements that firstly, areas of cloud be clearly identified and secondly, a maximum number of successive cloud-free days be employed in the analysis. MODIS level 2 C005 data has a stringent cloud screening process based on algorithms by Martins et al. [11] in which pixels classified as being fully or partially contaminated by cloud are "flagged" out of the data set. For a full description of the cloud masking procedure see Remer et al. [12]. Finally, for complete insurance that there is no residual contamination by clouds, an extra filter is utilised whereby pixels are "flagged" as cloudy if AOD in the infrared channel (1640 nm) exceeds 3 [13]. Additionally, it is desirable that wind speeds range from high to low, typically $4-20 \mathrm{~m} \mathrm{~s}^{-1}$ to provide a wind speed range comparable with Mulcahy et al. [5].

There are a number of uncertainties associated with satellite measurements, for example, the presence of clouds which are not removed by the filtering process, and whitecaps at high wind speeds lead to emissivity effects which can affect the quality of the retrieved MODIS AOD. More details can be read in Tanre et al. [14]. Other uncertainties arise as the two instruments are not collocated temporally or spatially. MODIS aqua has an equatorial crossing time 4.5 hours prior to that of QuikSCAT. Also interpolating the QuikSCAT grid from $0.25^{\circ}$ to $1^{\circ}$ can cause an uncertainty of up to $5 \%$. However, we aimed to reduce such uncertainties with 


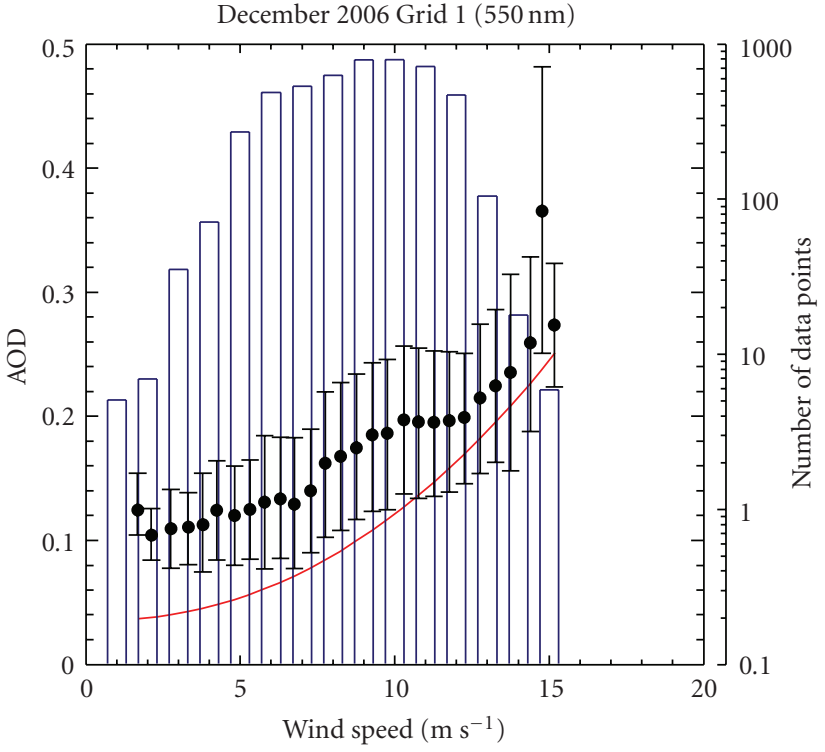

(a)

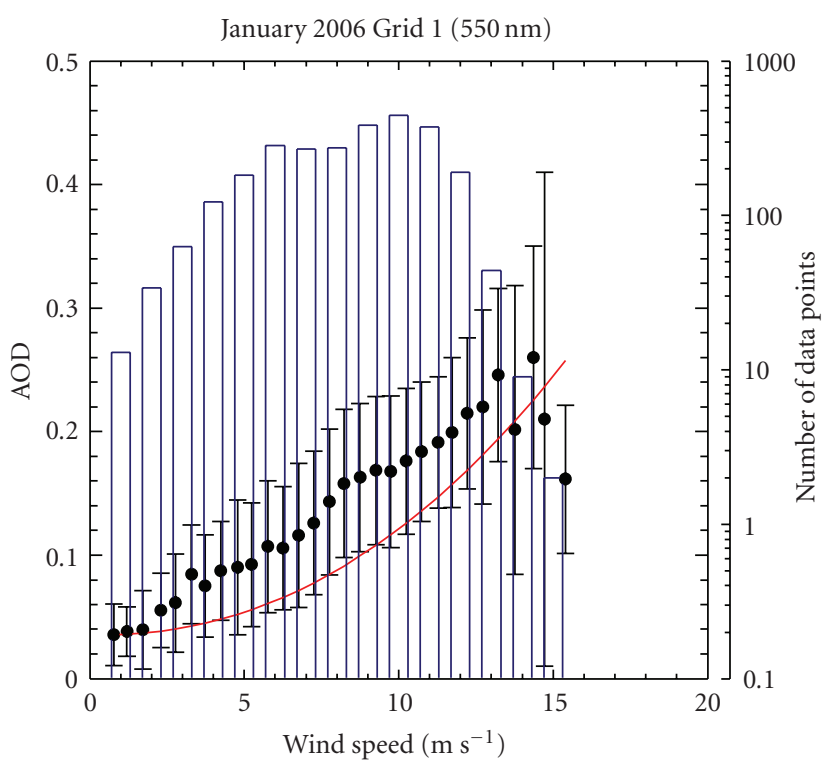

- AOD MODIS C005

- Mulcahy et al., [5]

$\square$ Number of data points

(c)

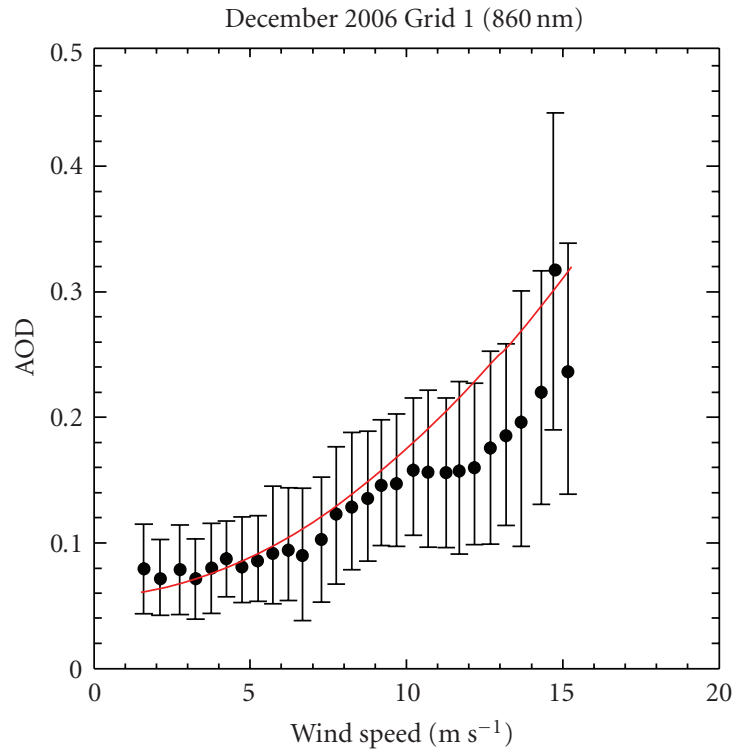

(b)

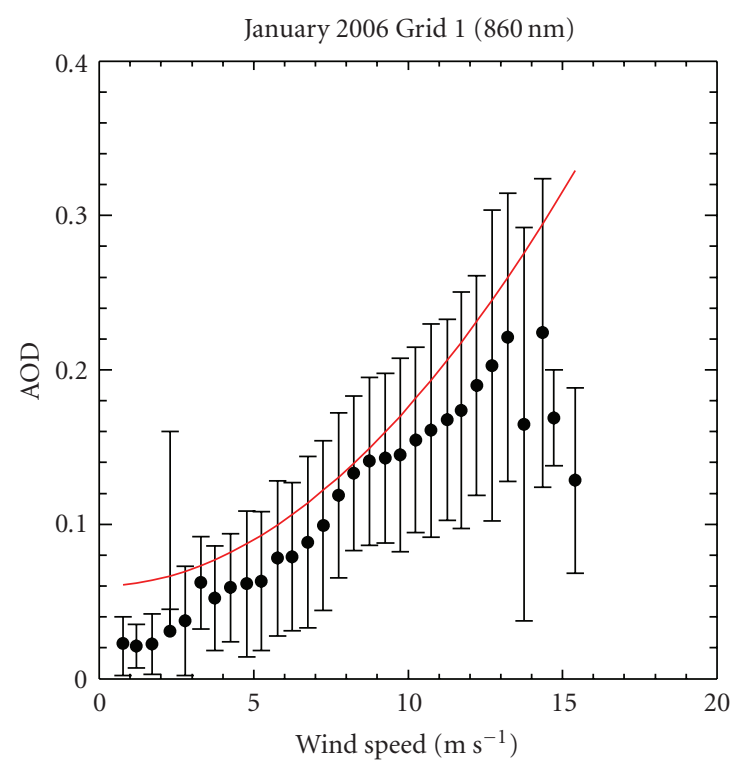

(d)

FIGURE 2: This Figure compares MODIS C005 AOD data at $550 \mathrm{~nm}$ and $860 \mathrm{~nm}$ (together with the standard deviation of AOD data within each bin) for Grid 1 during December and January 2006 with the Mulcahy et al. [5] AOD-wind speed relationship. Also shown is the number of data points per wind speed average bin.

the strict criteria with which our data was chosen. For all satellite instruments, calibration errors can lead to biases in the retrieved data. For MODIS aqua, Guenthar et al. [15] demonstrated a calibration error of between 1.8\%-1.9\%; however, this impact was deemed to be negligible on optical depth retrievals. The uncertainty in wind speed derived from QuikSCAT was shown to be approximately $1 \mathrm{~m} \mathrm{~s}^{-1}$, [16]. Sun glint and reflectance from whitecaps do result in a positive bias of $1 \%-10 \%$ for the MODIS AOD data which is within an acceptable degree of accuracy, [17].

\section{Evaluation of Satellite-Derived AOD versus Wind Speed}

Figures 2 and 3 present a comparison between AOD at $550 \mathrm{~nm}$ and $860 \mathrm{~nm}$ with wind speed for the two selected 


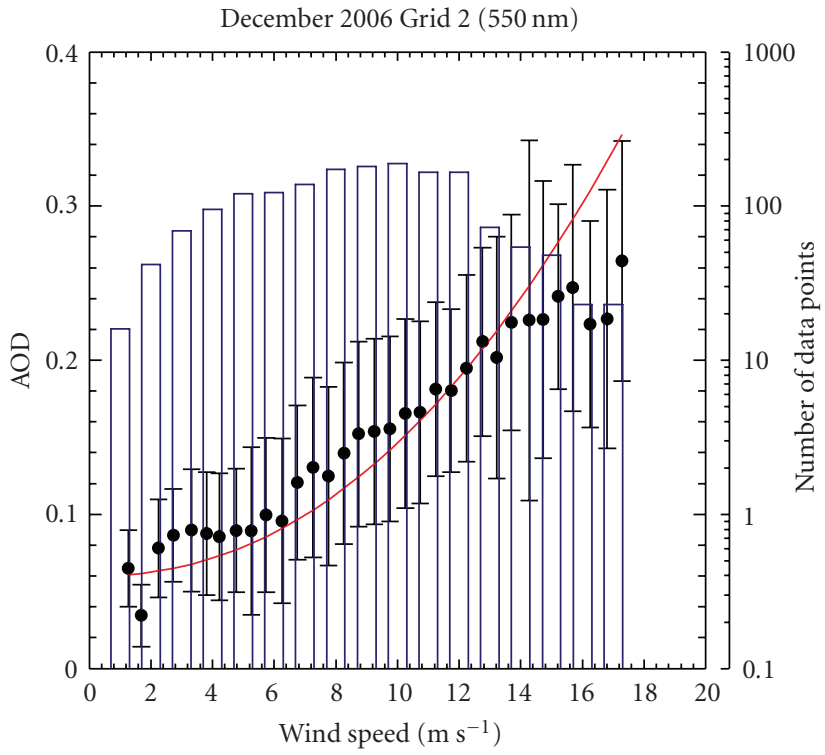

(a)

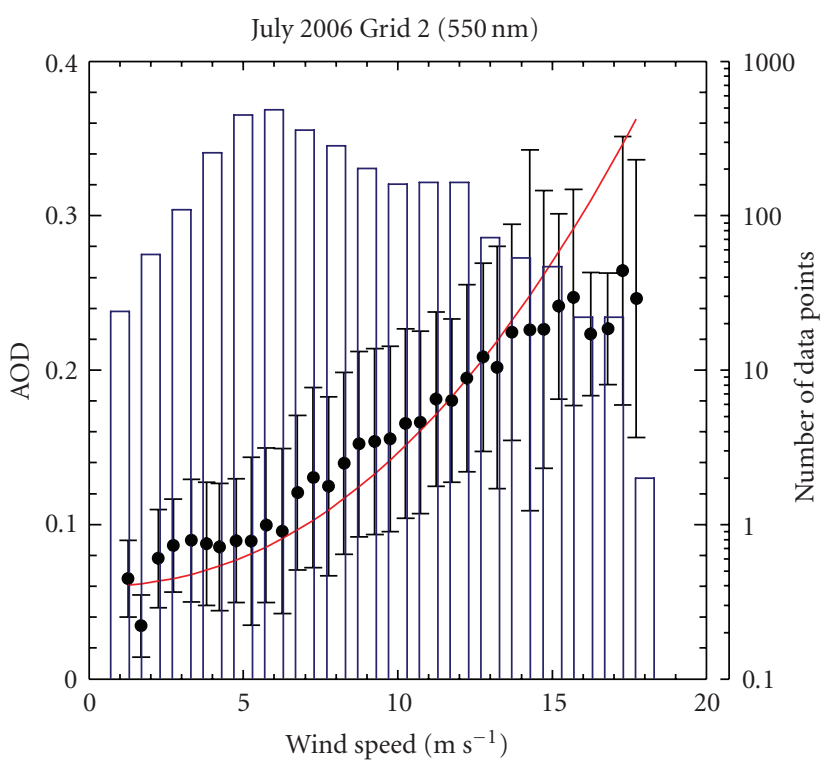

- AOD MODIS C005

- Mulcahy et al., [5]

$\square$ Number of data points

(c)

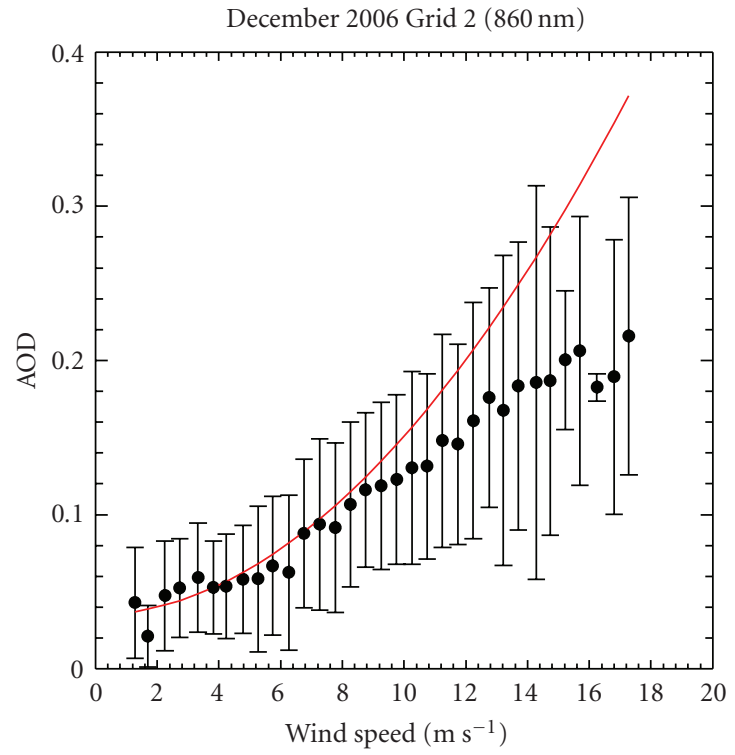

(b)

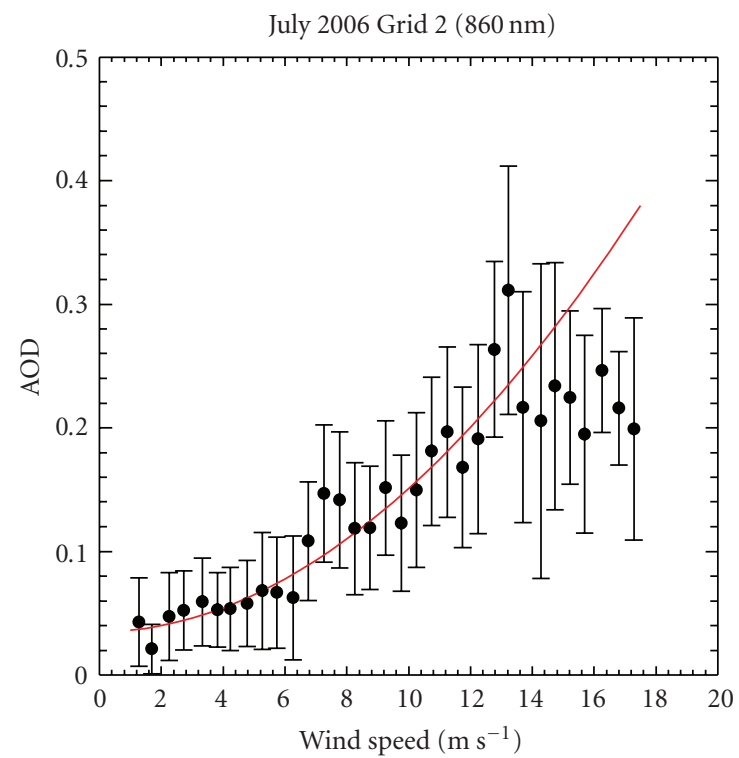

(d)

Figure 3: This Figure compares MODIS C005 AOD data at $550 \mathrm{~nm}$ and $860 \mathrm{~nm}$ (together with the standard deviation of AOD data within each bin) for Grid 2 during December and July 2006 with the Mulcahy et al. [5] AOD-wind speed relationship.

grids and for the two selected periods associated with each grid. Although not shown in the figures, the data were fitted using power-law regression equations, the parameters, and correlation coefficients which are given in Table 1.

\section{Results}

The results for Grid 1 during December and January 2006 are shown in Figure 2 and cover a wind speed range of
$2 \mathrm{~m} \mathrm{~s}^{-1}$ to $15 \mathrm{~m} \mathrm{~s}^{-1}$. For December, the $550 \mathrm{~nm}$ MODIS AOD is higher than the Mulcahy scheme for the lower wind speeds, increasing up to $10 \mathrm{~m} \mathrm{~s}^{-1}$ where it levels out between 10 and $13 \mathrm{~m} \mathrm{~s}^{-1}$, after which AOD increased again. For the $860 \mathrm{~nm}$ wavelength, there is excellent agreement with Mulcahy up to $10 \mathrm{~m} \mathrm{~s}^{-1}$, after which AOD levels out till it starts to increase with wind speed above $13 \mathrm{~m} \mathrm{~s}^{-1}$. For the January case, a similar trend is seen where in the $550 \mathrm{~nm}$ case, AOD is higher than that reported by Mulcahy, and for $860 \mathrm{~nm}$, AOD is 
TABle 1: Power-law fits for MODIS AOD versus wind speed for Grid 1 and Grid 2.

\begin{tabular}{lcr}
\hline Grid & $550 \mathrm{~nm}$ & $860 \mathrm{~nm}$ \\
\hline December Grid 1 & $\mathrm{AOD}=0.114+2.2 \times 10^{-4} \mathrm{U}^{2.47}$, & $\mathrm{AOD}=0.077+2.9 \times 10^{-4} \mathrm{U}^{2.36}$, \\
& $r^{2}=0.89$ & $r^{2}=0.91$ \\
January Grid 1 & $\mathrm{AOD}=-0.004+0.033 \mathrm{U}^{0.72}$, & $\mathrm{AOD}=-0.018+0.029 \mathrm{U}^{0.77}$, \\
& $r^{2}=0.91$ & $r^{2}=0.88$ \\
December Grid 2 & $\mathrm{AOD}=0.042+9.7 \times 10^{-4} \mathrm{U}^{1.09}$, & $\mathrm{AOD}=0.019+0.077 \mathrm{U}^{1.40}$, \\
July Grid 2 & $r^{2}=0.97$ & $r^{2}=0.97$ \\
& $\mathrm{AOD}=0.0395+0.011 \mathrm{U}^{1.04}$, & $\mathrm{AOD}=0.0387+0.117 \mathrm{U}^{1.015}$, \\
\hline
\end{tabular}

marginally lower than that in the Mulcahy parameterization. Between 9 and $13 \mathrm{~m} \mathrm{~s}^{-1}$, there is a slight reduction in the slope of the AOD-wind speed relationship, although not as drastic as the December case where it more or less levels off. The fitted power-law relationship for the December $550 \mathrm{~nm}$ case possessed an exponent of 2.47, and for the $860 \mathrm{~nm}$ wavelength, the exponent was 2.36. These exponents are slightly higher than the Mulcahy exponents $(2.2$ for $500 \mathrm{~nm}$ and 1.95 for the $832 \mathrm{~nm}$ wavelengths). For the January case, the exponents are significantly lower with a value of 0.72 for the $550 \mathrm{~nm}$ wavelength and 0.77 for the $860 \mathrm{~nm}$ wavelength. For these four relationships, the correlation coefficient $\left(r^{2}\right)$ was between 0.88 and 0.91 .

For Grid 2, shown in Figure 3, AOD values are observed over a wind speed range of 2 to $18 \mathrm{~m} \mathrm{~s}^{-1}$. For the December $550 \mathrm{~nm}$ case, excellent agreement between MODIS and Mulcahy is observed up to $\sim 16 \mathrm{~m} \mathrm{~s}^{-1}$, after which the MODIS AOD levels off as Mulcahy continues to increase. For $860 \mathrm{~nm}$, excellent agreement is seen up to $9-10 \mathrm{~m} \mathrm{~s}^{-1}$, after which MODIS AOD levels off.

For July, the Grid $2550 \mathrm{~nm}$ data shows very good agreement with Mulcahy, although MODIS produces slightly higher AOD values at lower wind speeds and slightly lower values at the higher wind speeds. For $860 \mathrm{~nm}$, the July data agree very well up to $15 \mathrm{~m} \mathrm{~s}^{-1}$, after which it levels off as the Mulcahy parameterization continues to rise with rising wind speed.

The fitted relationships for the December case between MODIS AOD and the Mulcahy scheme reflect a power law with an exponent of 1.09 for the $550 \mathrm{~nm}$ wavelength and 1.40 for the $860 \mathrm{~nm}$ wavelength. For the July case, the respective exponents are 1.04 and 1.02. The correlation coefficient for these 4 cases ranges from 0.83 to 0.97 .

\section{Discussion}

The MODIS-derived AOD-wind speed relationships follow a power law with an exponent ranging from below unity (0.72) to values greater than 2 (up to 2.47), with three out of the 8 cases have, more or less, a linear relationship with an exponent of $\sim 1$. As mentioned, Mulcahy found an exponent of $\sim 2.2$ for $500 \mathrm{~nm}$ and $\sim 2$ for $832 \mathrm{~nm}$. The variability of the MODIS values could be due to a number of reasons. In Grid 1, the December $550 \mathrm{~nm}$ case, relative to Mulcahy, reflects higher AOD at low wind speeds. There are three possibilities for these higher values: there is a significant fraction of secondary marine aerosol associated with these cases, thus contributing to enhanced AOD; there are high conditions of relative humidity, thus increasing the aerosol scattering potential; or the cases examined were influenced by long-range transport of anthropogenic aerosols, thus also contributing to the elevated AOD levels. The excellent agreement at low-to-moderate wind speeds for the $860 \mathrm{~nm}$ wavelength combined with the $550 \mathrm{~nm}$ date would suggest a significant fraction of submicron particles, either natural or anthropogenic, rather than an increase in relative humidity. As mentioned above, in this case, there was a levelling off in AOD at $10-13 \mathrm{~m} \mathrm{~s}^{-1}$, before continuing to increase above $13 \mathrm{~m} \mathrm{~s}^{-1}$. It is not clear what causes this trend; however, in most cases, at the highest wind speeds above $15 \mathrm{~m} \mathrm{~s}^{-1}$, the MODIS-derived AOD is less than that in the Mulcahy parameterization. For wind speeds less than $15 \mathrm{~m} \mathrm{~s}^{-1}$, there is more often than not very good agreement between the two datasets, although there is still some variability in overestimation and underestimation by MODIS relative to Mulcahy. Our results should also be compared to some recent satellite-derived AOD-wind speed relationships. Huang et al. [18] found a linear relationship between AOD and wind speed ranging from $\sim 0.08-0.09$ at zero $\mathrm{m} \mathrm{s}^{-1}$ to $\sim 0.15-$ 0.175 at $20 \mathrm{~m} \mathrm{~s}^{-1}$. It should be noted that, for the same wavelength, Mulcahy estimates a lower wind speed AOD value of 0.04 or less, and at the highest wind speed measured by Mulcahy $\left(18 \mathrm{~m} \mathrm{~s}^{-1}\right)$, AOD is greater $(\sim 0.35)$. By comparison, Lehahn et al. [19] found similarly low wind speed values as Mulcahy (0.04 or less) and values of about 0.18 at a wind speed of $14 \mathrm{~m} \mathrm{~s}^{-1}$ compared to values of $\sim$ 0.24 [5], but with a significantly lower correlation coefficient $(R \sim 0.45-0.5)$. The Huang et al. [18] satellite AOD study, relative to the Mulcahy ground-based AOD study, tends to overestimate AOD by about $100 \%$ under conditions of zero wind speed and underestimate AOD at the higher wind speeds of $18-20 \mathrm{~m} \mathrm{~s}^{-1}$ by a similar amount. Lehahn et al. [19] provide better agreement with Mulcahy at the lower wind speeds (less than $\sim 12 \mathrm{~m} \mathrm{~s}^{-1}$ ); however, at their maximum reported wind speeds of less than $15 \mathrm{~m} \mathrm{~s}^{-1}$, their AOD values are about $25 \%$ less than that reported by Mulcahy et al. [5].

It should be noted that AOD derived from the precision filter radiometer is a more direct measurement, and many more assumptions are required in the MODIS retrieval 
algorithm than in the precision filter radiometer. Consequently, one would expect the radiometer data to reflect the more accurate AOD-wind speed relationship. In addition, and as stated in the introduction, a detailed modeling study of sea spray production and associated AOD also concluded a power law with an exponent of 2 [8]. Finally, meteorological effects such as increased deposition rates may be associated with stable boundary layers would reduce the spray residence time, thus reducing its AOD impact; variations in precipitation rates or long-range transport of anthropogenic aerosols can all contribute to the variability in the MODIS cases. Nevertheless, the main conclusions arrived at by Mulcahy et al. [5] still hold, namely, that sea spray contributions to marine AOD can approach or even exceed values of 0.3 and that natural sea spray under moderately high wind speed regimes can rival that of many anthropogenic plumes advecting out into marine environments.

\section{Conclusions}

MODIS-derived AOD for clean, remote maritime conditions are analysed as a function of wind speeds ranging from 2 to $18 \mathrm{~m} \mathrm{~s}^{-1}$. The relationships observed followed a power law with exponents ranging from 0.72 to 2.47 for $550 \mathrm{~nm}$ wavelengths and from 0.75 to 2.40 for the $860 \mathrm{~nm}$ wavelength. The MODIS-derived AOD was compared to the Mulcahy parameterization derived from a precision filter radiometer at a coastal NE Atlantic station (Mace Head). Generally, good agreement was found between the two datasets, although, on a case by case basis, sometimes MODIS overestimated and sometimes underestimated relative to Mulcahy. Mostly, MODIS-delivered lower AOD values at higher wind speeds $\left(>15 \mathrm{~m} \mathrm{~s}^{-1}\right)$ when compared to Mulcahy, and at times, overestimated at lower wind speeds, resulting in an exponent close to 1, producing a linear relationship between AOD and wind speed at times. There are a number of reasons for the variability in the MODIS derived AOD-wind speed exponent. These include the possibility of variability in meteorology (i.e., precipitation and stability) which may reduce sea spray residence time, long range transport of anthropogenic aerosol, secondary marine aerosol production, and variability in relative humidity fields, altering aerosol scattering efficiency. While there is variability in MODIS-derived AOD versus wind speed, with the parameterized exponent deviating from the Mulcahy squared power law dependency, there is no reason to suggest that a power law with an exponent of 2.2 for $500 \mathrm{~nm}$, and 2 for $860 \mathrm{~nm}$ is not a robust parameterization. The results also support the suggestion that wind-generated sea spray, under moderately high winds, can rival anthropogenic pollution plumes advecting out into marine environments with wind driven AOD contributing to AOD values approaching 0.3 .

\section{Acknowledgments}

This work was supported by the Irish Environmental Protection Agency. The authors also wish to acknowledge the World Optical Depth Research and Calibration Centre (WORCC) and Senior Scientist Christoph Wehrli and his team for facilitation of the quality-controlled PFR AOD data at Mace Head.

\section{References}

[1] S. Solomon, D. Qin, M. Manning et al., Climate Change 2007: The Physical Science Basis. Contribution of Working Group 1 to the Fourth Assessment Report of the Intergovernmental Panel on Climate Change, Cambridge University Press, Cambridge, UK, 2007.

[2] C. D. O'Dowd and G. De Leeuw, "Marine aerosol production: a review of the current knowledge," Philosophical Transactions of the Royal Society A, vol. 365, no. 1856, pp. 1753-1774, 2007.

[3] C. D. O’Dowd, J. A. Lowe, M. H. Smith, and A. D. Kaye, "The relative importance of non-sea-salt sulphate and seasalt aerosol to the marine cloud condensation nuclei population: an improved multi-component aerosol-cloud droplet parametrization," Quarterly Journal of the Royal Meteorological Society, vol. 125, no. 556, pp. 1295-1313, 1999.

[4] C. Kleefeld, C. D. O'Dowd, S. O'Reilly et al., "Relative contribution of submicron and supermicron particles to aerosol light scattering in the marine boundary layer," Journal of Geophysical Research D, vol. 107, no. 19, article 8103, 2002.

[5] J. P. Mulcahy, C. D. O’Dowd, S. G. Jennings, and D. Ceburnis, "Significant enhancement of aerosol optical depth in marine air under high wind conditions," Geophysical Research Letters, vol. 35, no. 16, Article ID L16810, 2008.

[6] C. D. O’Dowd, M. C. Facchini, F. Cavalli et al., "Biogenically driven organic contribution to marine aerosol," Nature, vol. 431, no. 7009, pp. 676-680, 2004.

[7] T. S. Bates, T. L. Anderson, T. Baynard et al., "Aerosol direct radiative effects over the northwest Atlantic, northwest Pacific, and North Indian Oceans: estimates based on in-situ chemical and optical measurements and chemical transport modeling," Atmospheric Chemistry and Physics, vol. 6, no. 6, pp. 16571732, 2006.

[8] W. L. Madry, O. B. Toon, and C. D. O'Dowd, "Modeled optical thickness of the sea salt aerosol over the world ocean," submitted to Journal of Geophysical Research.

[9] A. Smirnov, B. N. Holben, Y. J. Kaufman et al., "Optical properties of atmospheric aerosol in maritime environments," Journal of the Atmospheric Sciences, vol. 59, no. 3, pp. 501-523, 2002.

[10] R. R. Draxler and G. D. Hess, "An overview of the HYSPLIT_4 modelling system for trajectories, dispersion and deposition," Australian Meteorological Magazine, vol. 47, no. 4, pp. 295308, 1998.

[11] J. V. Martins, D. Tanré, L. Remer, Y. Kaufman, S. Mattoo, and R. Levy, "MODIS cloud screening for remote sensing of aerosols over oceans using spatial variability," Geophysical Research Letters, vol. 29, no. 12, Article ID 8009, 4 pages, 2002.

[12] L. A. Remer, Y. J. Kaufman, D. Tanré et al., "The MODIS aerosol algorithm, products, and validation," Journal of the Atmospheric Sciences, vol. 62, no. 4, pp. 947-973, 2005.

[13] A. Smirnov, B. N. Holben, T. F. Eck, O. Dubovik, and I. Slutsker, "Cloud-screening and quality control algorithms for the AERONET database," Remote Sensing of Environment, vol. 73, no. 3, pp. 337-349, 2000.

[14] D. Tanré, Y. J. Kaufman, M. Herman, and S. Mattoo, "Remote sensing of aerosol properties over oceans using the MODIS/EOS spectral radiances," Journal of Geophysical Research D, vol. 102, no. 14, pp. 16971-16988, 1997. 
[15] B. Guenther, X. Xiong, V. V. Salomonson, W. L. Barnes, and J. Young, "On-orbit performance of the Earth observing system moderate resolution imaging spectroradiometer; first year of data," Remote Sensing of Environment, vol. 83, no. 1-2, pp. 1630, 2002.

[16] W. T. Liu, "Progress in scatterometer application," Journal of Oceanography, vol. 58, no. 1, pp. 121-136, 2002.

[17] L. A. Remer, D. Tanre, and Y. J. Kaufman, "Algorithm theoretical basis document (ATBD): algorithm for remote sensing of tropospheric aerosol from MODIS," Collection 5, Product ID: MOD04/MYD04, 2006.

[18] H. Huang, G. E. Thomas, and R. G. Grainger, "Relationship between wind speed and aerosol optical depth over remote ocean," Atmospheric Chemistry and Physics, vol. 10, no. 13, pp. 5943-5950, 2010.

[19] Y. Lehahn, I. Koren, E. Boss, Y. Ben-Ami, and O. Altaratz, "Estimating the maritime component of aerosol optical depth and its dependency on surface wind speed using satellite data," Atmospheric Chemistry and Physics, vol. 10, no. 14, pp. 67116720, 2010. 

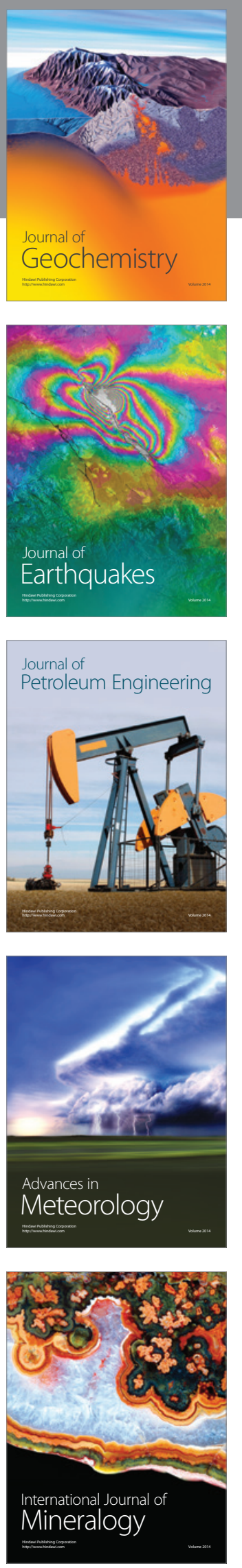
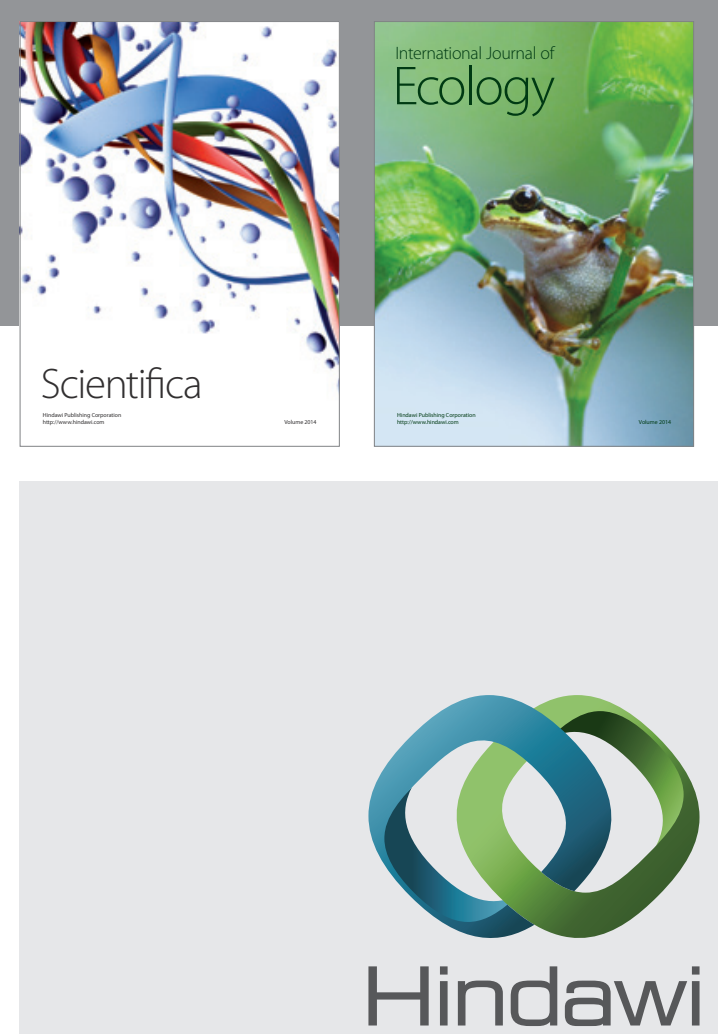

Submit your manuscripts at http://www.hindawi.com
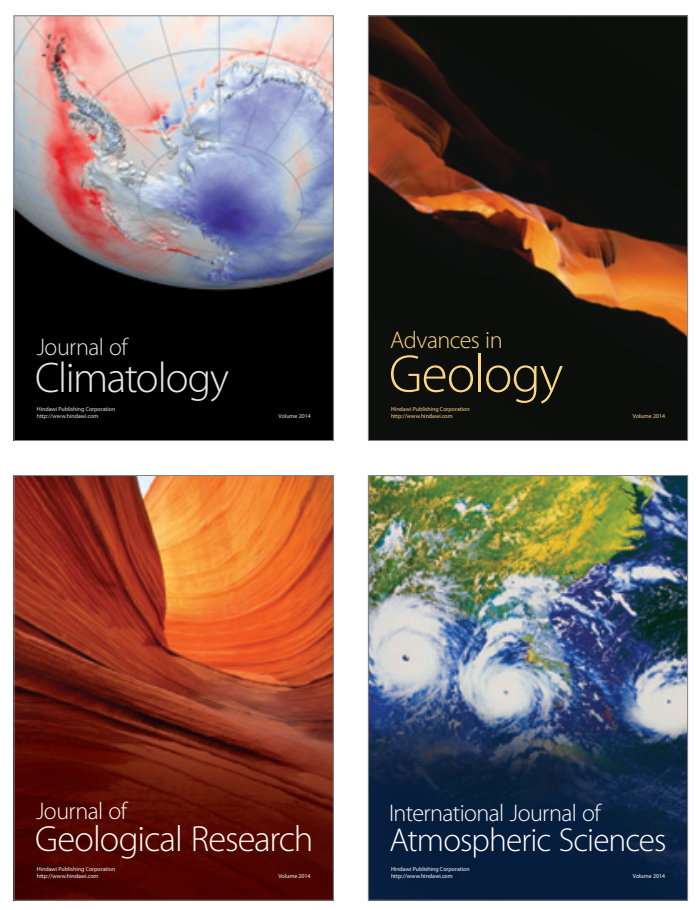
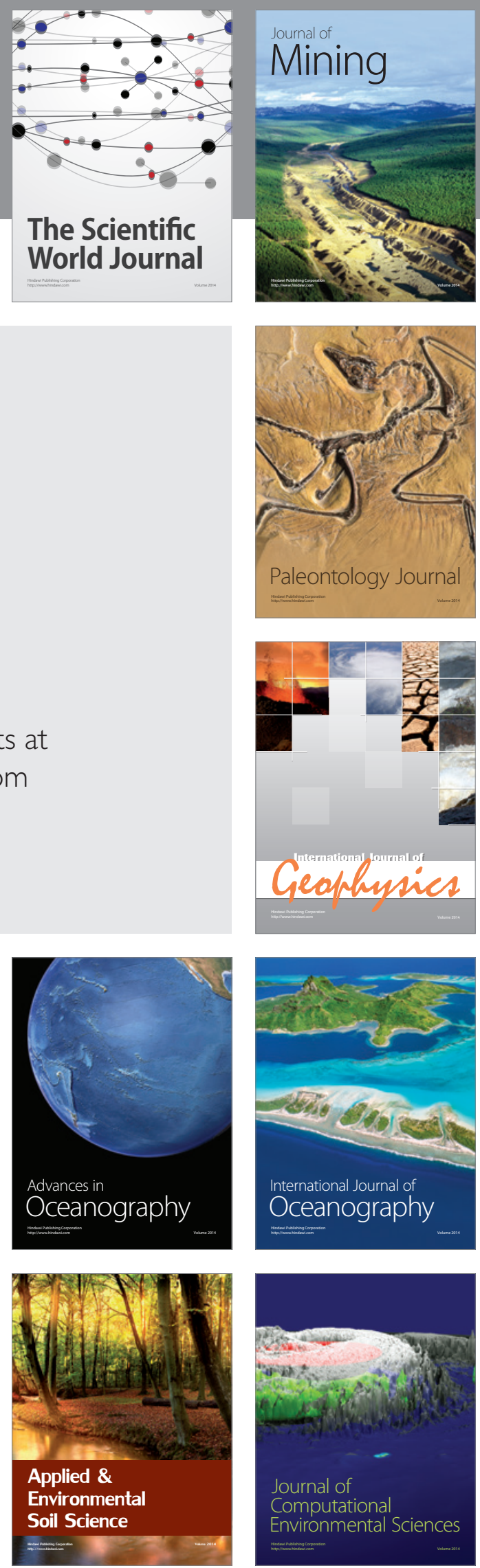